University of Nebraska - Lincoln

DigitalCommons@University of Nebraska - Lincoln

Faculty Publications, Department of Psychology

Psychology, Department of

November 1999

\title{
Perceptions of Couple Functioning Among Female Survivors of Child Sexual Abuse
}

David DiLillo

University of Nebraska-Lincoln, ddilillo@unl.edu

Patricia J. Long

Oklahoma State University, plong2@ulv.edu

Follow this and additional works at: https://digitalcommons.unl.edu/psychfacpub

Part of the Psychiatry and Psychology Commons

DiLillo, David and Long, Patricia J., "Perceptions of Couple Functioning Among Female Survivors of Child Sexual Abuse" (1999). Faculty Publications, Department of Psychology. 173.

https://digitalcommons.unl.edu/psychfacpub/173

This Article is brought to you for free and open access by the Psychology, Department of at DigitalCommons@University of Nebraska - Lincoln. It has been accepted for inclusion in Faculty Publications, Department of Psychology by an authorized administrator of DigitalCommons@University of Nebraska - Lincoln. 


\title{
Perceptions of Couple Functioning Among Female Survivors of Child Sexual Abuse
}

\author{
David DiLillo \\ Patricia J. Long
}

\begin{abstract}
A sample of 51 college women retrospectively reporting a history of childhood sexual abuse and 91 women failing to report such a history was examined in order to investigate the relationship between victimization history and survivors' self-reports of functioning in adult intimate relationships. Specifically, relationship satisfaction, communication, and trust were examined in heterosexual relationships of at least six months' duration. As hypothesized, even when demographic differences between groups were controlled, survivors reported significantly less relationship satisfaction, poorer communication, and lower levels of trust in their partners than did women with no history of sexual abuse. The implications of these results are discussed with regard to clinical applications and future research. [Article copies available for a fee from The Haworth Document Delivery Service: 1-800-342-9678. E-mail address: getinfo@haworthpressinc.com]
\end{abstract}

KEYWORDS. Child sexual abuse, relationship functioning, marital satisfaction

David DiLillo, PhD, is Assistant Research Professor in the Department of Psychology at the University of Missouri-Columbia. His research interests in the area of child sexual abuse focus upon the long-term adjustment of survivors in their adult relationships. Patricia J. Long, PhD, is Associate Professor of Clinical Psychology at Oklahoma State University. Her research examines the adult adjustment of survivors of childhood sexual abuse and factors which may explain variations in functioning in these women.

Address correspondence to: David DiLillo, PhD, Department of Psychology, University of Missouri-Columbia, 210 McAlaster Hall, Columbia, MO 65211.

Submitted for publication 3-16-98; revised 7-14-98; accepted 10-30-98.

Journal of Child Sexual Abuse, Vol. 7(4) 1999

(C) 1999 by The Haworth Press, Inc. All rights reserved. 
In recent years a significant amount of research has been generated on the prevalence of childhood sexual abuse (CSA) and its long-term consequences. Estimates of the prevalence of sexual abuse in women range from between 20\% and 40\% (Peters, Wyatt, \& Finkelhor, 1986; Salter, 1992). Adults with a history of childhood sexual abuse have been found to differ from nonvictims on a wide range of characteristics (Browne \& Finkelhor, 1986; Polusny \& Follette, 1995). For instance, compared to women with no history of abuse, child sexual abuse survivors are at greater risk to develop depression and anxiety disorders (Briere \& Runtz, 1988; Yama, Tovey, \& Fogas, 1993). Survivors also report higher rates of alcohol and substance abuse (Peters, 1988), eating disturbances (Conners \& Morse, 1993), and personality disorders, particularly Borderline Personality Disorder (Herman, Perry, \& van der Kolk, 1989; Linehan, 1993).

The majority of research to date has focused upon the association between childhood sexual abuse and specific mental health problems. Recently, however, investigators have begun to explore the long-term impact of CSA upon other areas of adjustment, such as general interpersonal functioning. In one such study, Jackson, Calhoun, Amick, Maddever, and Habif (1990) employed the Social Adjustment Scale (SAS) to assess survivors' interpersonal interactions. Results showed that college-aged incest survivors experienced more problems in the area of dating and other social leisure-time activities than did their nonabused counterparts. Harter, Alexander, and Neimeyer (1988) also used the SAS to study survivors' social adjustment, and found that abused subjects reported significantly poorer adjustment than those with no history of abuse. Regarding sexual functioning, there is abundant evidence that survivors experience a variety of sexual problems, including decreased sexual satisfaction, increased sexual dysfunction, and a tendency to engage in multiple, short-term sexual relations (Jackson et al., 1990; Wyatt, 1988). Additionally, female survivors of CSA are more likely than nonabused women to suffer physical or sexual abuse in their adult relationships with men (Wind \& Silvern, 1992; Wyatt, Guthrie, \& Notgrass, 1992). Finally, in one of the few studies to examine perceptions of parental functioning among CSA survivors, Cole, Woolger, Power, and Smith (1992) found that adult women abused by their fathers reported greater feelings of inadequacy and distress about parenting than did nonabused women or women with alcoholic fathers. Together, these studies reveal that CSA is very 
likely a contributing factor in a variety of interpersonal relationship difficulties.

A significant aspect of interpersonal functioning which has received very little attention concerns survivors' adult couple relationships. Numerous clinical writings have documented the detrimental effects of CSA upon adult couples in which one partner was victimized as a child (e.g., Davis, 1991; Engle, 1991; Gil, 1992; Graber, 1991; Hansen, 1991; Kritsberg, 1990; Maltz, 1988; Stark, 1993). Only a few empirical studies (e.g., Finkelhor, Hotaling, Lewis, \& Smith, 1989; Mullen, Martin, Anderson, Romans, \& Herbison, 1994) have included relationship variables, usually within the context of larger surveys. These investigations have tended to use vaguely delineated criteria for identifying survivors, and have rarely employed standardized, psychometrically-sound instruments to evaluate specific survivor relationship characteristics. The absence of detailed studies focusing primarily upon survivors' relationships with their partners has resulted in a significant deficit in current knowledge of the impact of CSA upon a very important aspect of survivors' interpersonal functioning. This study serves as an initial, in-depth investigation into specific relationship characteristics thought to be influenced by a history of CSA.

Survivors' overall satisfaction in their couple relationships is one area likely to be impacted by CSA. The myriad emotional and behavioral problems often associated with sexual abuse may interfere with healthy couple functioning, resulting in lower levels of relationship satisfaction. Previous studies examining survivors' satisfaction in their adult couple relationships have yielded somewhat discrepant findings. In a nationally representative sample of 2626 women, Finkelhor, Hotaling, Lewis, and Smith (1990) found that survivors were more likely than nonabused women to report marital disruption in the form of divorce or separation from their partners, suggesting a lower level of relationship satisfaction among survivor couples. Similarly, Hunter (1991) reported that survivors displayed poorer adjustment than nonvictims in a number of psychosocial areas, including relationship satisfaction, as measured by the Dyadic Adjustment Scale (DAS). Waltz (1996) assessed survivors' relationship satisfaction via two measures, the DAS and the Marital Satisfaction Index (MSI). Again, survivor relationships were found to be less satisfactory as measured by the DAS, but no differences in satisfaction were found on the MSI. In a final study employing the DAS, survivor couples were found to be no 
less satisfied with their relationships than nonvictim couples, despite reporting higher levels of overall conflict in their relationships (Serafin \& Follette, 1996). Thus, findings are currently inconclusive regarding the association between CSA and survivors' satisfaction in their adult partner relationships. Further investigation is needed to clarify this relationship.

Female survivors of CSA may experience difficulties trusting their partners. In Finkelhor and Browne's (1985) four traumagenic dynamics model, one of the dynamics, betrayal, may bear specifically upon trust issues. Because sexual abuse occurs when adults (often family members) deceive a child, survivors may suffer impairment in their ability to trust others. This impairment may be manifested in a diminished ability to trust in their adult relationships with partners. From a developmental perspective, it has also been proposed that incest violates children's basic beliefs about trust with emotionally significant people, resulting in distrust, insecurity, and suspiciousness in adult relationships (Cole \& Putnam, 1992). These notions are supported by findings that a significant percentage $(79 \%)$ of incest survivors report feelings of fear, mistrust, hostility, and a sense of betrayal in their relationships with men (Courtois, 1979). Mullen et al. (1994) surveyed over 2000 adult women in order to compare survivors' and nonabused women's functioning in a variety of social, interpersonal, and sexual areas. In this study, women with a history of abuse were significantly more likely than nonabused women to have difficulties confiding in and discussing personal concerns with their partners. Thus, currently, some empirical evidence points to a link between CSA and survivors' capacities to trust their partners. However, further inquiry is needed to gain a more complete understanding of this association.

A third area of couple functioning that may be adversely impacted by CSA is communication. Based upon interviews with survivors of CSA, Davis (1991) speculates that, because many incest survivors were forced to conceal their abuse as children, secrecy may have become an ingrained pattern for them, resulting in less open, direct communication with their partners as adults. Indeed, in the only study to examine this relationship, Mullen et al. (1994) found that $23 \%$ of survivors reported that they had "no meaningful communication" with their partners, whereas only $6 \%$ of nonabused women said the same-a difference that was statistically significant. Clearly, more research 
is needed if the impact of CSA upon couple communication patterns is to be elucidated.

Despite an abundance of clinical literature attesting to the deleterious effects of CSA upon survivors' relationships with partners, very few empirical studies have systematically investigated survivors' perceptions of functioning in the context of their couple relationships. In this study, abused and nonabused women's reports of relationship satisfaction, trust, and communication were compared in order to explore the relationship between CSA and survivors' relationships with partners. It was expected that survivors would report poorer functioning with their partners in each of these three areas.

The present investigation was intended to address several methodological deficiencies found in much of the existing literature on survivors' couple functioning. First, in contrast to many studies reviewed here, the current investigation employed a clear and stringent definition of sexual abuse obtained from a well-accepted measure of abuse history. Second, this study also used well-standardized measures of relationship characteristics, rather than simply utilizing a few questions which may lack reliability and validity. Finally, in contrast to most previous research, the present investigation expands current knowledge of survivors' relationship functioning by including unmarried as well as married women who were in committed relationships.

\section{METHOD}

\section{Participants}

Participants were 412 female college students recruited from a psychology department research participant pool for a study examining the effects of childhood experiences on adjustment and received class credit for participation in the study. Responses to the LEQ (described below) were used to differentiate those participants who had been victimized as a child from those who had not. Initially, women responded to a series of questions asking whether as a child (under the age of 18), they had any sexual experiences. Subjects were instructed to exclude any voluntary sexual activities between themselves and a dating partner and any consensual sexual play with a peer, provided the age difference between subject and partner was less than five 
years. Following these screening questions, subjects provided more specific information about their sexual experiences. From these data, the following criteria were used to identify those subjects who had experienced childhood sexual abuse: the abuse for each survivor must have included physical contact; and the age difference between perpetrator and victim must have been equal to or greater than five years, or if less than a five year age difference, a subject must have reported the use of force or the threat of force for the experience to have been considered abusive. Further, all sexual experiences with family members, regardless of the age difference between victim and perpetrator, were classified as abusive.

Of the 412 women recruited to participate in this study, 12 did not provide enough information for survivor status to be determined and were therefore excluded from further analysis. Among the remaining 400 subjects, 309 subjects were classified as not having experienced sexual abuse and 91 were classified as survivors.

It was reasoned that those subjects involved in relatively new relationships would not be sufficiently familiar with their partners to report reliably about their long-term perceptions of trust, communication, and satisfaction. Therefore, six months was chosen as the minimum length of time of involvement in a relationship for inclusion in the present study. From the larger group of 400, 51 survivors and 115 nonabused women met this criteria of currently being involved in a monogamous heterosexual relationship for six months or longer, and were included in this study.

Participants ranged in age from 17 to 51 years, with a mean age of 20.0 years $(S D=3.9)$. Of these women, $86.1 \%$ reported that they were not married at the time of the study (i.e., they had never been married or were currently separated or divorced), while $13.9 \%$ were married or cohabitating at the time of the study. Socioeconomic status was assessed using the two-factor index of social position (Myers \& Bean, 1968 ), and ranged from upper to lower socioeconomic class with the average participant falling in the middle class. The majority of women were Caucasian (89.7\%), while 2.4\% were African American, 2.4\% were Hispanic, $3.6 \%$ were Native American, and $1.8 \%$ were Asian.

Those participants identified as survivors were also asked to report on various characteristics of their abuse experiences. When indicating the most severe level of abuse which occurred, $2 \%$ of the 51 survivors reported kissing, $27.5 \%$ reported non-genital fondling, $35.3 \%$ reported 
genital fondling, 9.8\% reported oral-genital contact, and $25.5 \%$ reported anal or vaginal intercourse. (Note: Survivors were categorized by their most serious experience so that percentages still add to 100). In terms of duration of abuse, $46.9 \%$ of the survivors were abused for one month or less, $16.3 \%$ were abused for one to six months, and $36.7 \%$ were abused for longer than six months. Force was used during the abuse with $43.1 \%$ of the survivors. The majority of women (56.0\%) were victimized by a perpetrator from outside the family, while $44.0 \%$ reported intrafamilial abuse. Of the 51 survivors in the sample, $96.1 \%(n=49)$ had male perpetrators, whereas only 2 women $(3.9 \%)$ were sexually abused by females.

\section{Measures}

Life Experiences Questionnaire (LEQ). The LEQ is a self-report instrument, developed by the second author and colleagues, that includes questions regarding demographics and childhood sexual experiences (Long, 1998), and is based on the Past Experiences Questionnaire (a self-report instrument with demonstrated reliability; Messner et al., 1988). Childhood sexual abuse was screened with a series of eight questions asking participants whether as a child (under age 18), they had any sexual experiences, ranging from someone exposing themselves to the participant, to having engaged in intercourse with someone. Subjects were instructed to exclude any voluntary sexual activities between themselves and a dating partner and any consensual sexual play with a peer as long as the partner, in either case, was no more than five years older than the subject. Information regarding specific sexual experiences was then assessed. Sexual abuse was defined as contact abuse only (excluding noncontact experiences such as exhibitionism) and must have met at least one of the following criteria: (1) abuse perpetrated by a relative, (2) greater than five years age difference between the victim and perpetrator, or (3) if less than five year age difference between the victim and perpetrator, threat or force was involved.

Two-week test-retest reliability has been assessed for the LEQ with a sample of 145 women and is good (Long, 1998). Percent agreement on items related to the identity of perpetrator (intrafamilial versus extrafamilial, $94 \%, \chi^{2}(1)=26.8, p<.0001$ ), duration of abuse (abuse lasting less than one month, between one and six months, longer than six months, $88 \%, \chi^{2}(4)=44.6, p<.0001$ ), whether abuse was contact 
versus noncontact $\left(97 \%, \chi^{2}(1)=17.0, p<.0001\right)$, self-perception of whether CSA was experienced (yes, no, not sure, $89 \%, \chi^{2}(2)=23.1$, $p<.0001$ ), the nature of the sexual abuse (vaginal or anal intercourse, penetration of the vagina or anus by objects, oral-genital contact, genital fondling, nongenital fondling, $80 \%, \chi^{2}(16)=81.6, p<.0001$ ), and presence or absence of force $\left(71 \%, \chi^{2}(1)=6.4, p<.01\right)$ all indicate a reliable scale. Similar results are seen in reliabilities for items such as the age of onset of abuse $(r=.99, p<.0001)$, the age of the perpetrator $(r=.96, p<.0001)$, and the age difference between victim and perpetrator $(r=.96, p<.0001)$.

Quality Marriage Index (QMI; Norton, 1983). The QMI is a six item self-report questionnaire designed to measure overall marital/ relationship satisfaction. Sample items include "My relationship with my partner makes me happy" and "I really feel like part of a team with my partner." Higher scores on the QMI indicate greater relationship satisfaction. For the first five questions, subjects respond on a 7-point Likert scale ranging from 1 (very strongly disagree) to 7 (very strongly agree). The final question is on a 10-point scale ranging from 1 (very unhappy) to 10 (perfectly happy). A total score is computed by standardizing each item to a mean of 0 and a standard deviation of 1 , then summing the seven items in the scale.

Norton (1983) provides several findings supporting the validity of the QMI. He reports that as scores on the QMI increase, similarity in attitudes between partners also increases. Very low QMI scores have been shown to be related to low estimates of times that couples will remain together (Norton, 1983). Norton (1983) also reports that couples with lowest QMI scores are the most likely to talk often about ending their relationships. Finally, the items on the QMI are correlated highly with each other, with correlations ranging from .68 to .86 (Norton, 1983).

Specific Interpersonal Trust Scale-Female Form (SITS; JohnsonGeorge \& Swap, 1982). The SITS-Female Form is a self-report questionnaire designed to measure an individual's trust in her partner. Subjects respond to questions on a 9-point scale ranging from 1 (strongly disagree) to 9 (strongly agree), with higher scores indicating greater levels of interpersonal trust. The SITS-Female Form consists of 13 items which load onto two subscales referred to as Reliableness and Emotional Trust. Sample items include: "If [my partner] promised to do me a favor, he or she would follow through" (Reliableness), and 
"[My partner] would never intentionally misrepresent my point of view to others" (Emotional Trust). The SITS is scored by calculating a mean of the scores from each subscale, which can range from one through nine.

The SITS consists of two forms (for male and female reporters) and five total subscales. The male form contains three subscales, and female form contains the remaining two. Coefficient alphas for the five subscales were reported as ranging from .71 to .83 (Johnson-George \& Swap, 1982), indicating that the reliability of the Female form falls within acceptable limits. The subscales demonstrate discriminability from other positive interpersonal attitudes such as liking and loving. Factor analysis of subjects' responses to items of the Rubin (1970) Liking and Loving Scales and items of the SITS provide evidence that trust can be measured separately from other related constructs. Factor analysis conducted by Johnson-George and Swap (1982) also supports the existence of two subscales for women. The discriminant validity of the Reliableness and Emotional Trust subscales has also been supported by results of experiments showing that each subscale can be differentially influenced by experimental manipulation (JohnsonGeorge \& Swap, 1982).

Marital Communication Inventory (MCI; Bienvenu, 1970). The $\mathrm{MCI}$ is a self-report questionnaire designed to assess communication patterns in marriages and other long-term monogamous relationships. Form $\mathrm{F}$ for females contains 46 items answered on a 4-point scale ranging from 0 (never) to 3 (usually). The MCI is scored by summing the raw scores to obtain one total score, which can range from 46 to 184; higher total scores are indicative of better couple communication. The items vary widely in content, measuring perceptions of partner's attitudes and behaviors, as well as the subject's self-perceived attitudes and behaviors (e.g., "Do you feel your partner says one thing but means another?" and "Does your partner listen to what you have to say?"). The psychometric properties of the MCI make it useful as a research instrument. The MCI has been shown to have excellent splithalf reliability $(=.93$, Bienvenu, 1970$)$, and similarly high test-retest reliability over a five week period $(=.92$, Schumm \& Jackson, 1980$)$. Validity of the MCI has also been supported. The MCI has been found to correlate quite well with other communication inventories such as the Primary Communication Inventory (Collins, 1977; Guerney, 1977). 


\section{Procedure}

All self-report data were obtained as part of a larger ongoing project examining the effects of childhood sexual abuse on later adjustment. Questionnaires were administered in group sessions conducted by psychology graduate students. After informed consent was obtained, participants completed the Life Experiences Questionnaire, Quality Marriage Index, Specific Interpersonal Trust Scale, and the Marital Communication Index, as well as several other instruments not discussed here. All instruments were administered to subjects in a random order.

\section{RESULTS}

Initially, a series of Chi-square analyses and $t$-tests were conducted to compare survivors and nonabused women on the demographic characteristics of age, SES, marital status, and race. Results indicated that survivors tended to be from a lower socioeconomic status $(M=$ $30.7, S=15.7)$ than nonabused women $(M=26.2, S=13.0), t(158)=$ $1.89, p<.06$, and that survivors tended to be older $(M=20.8, S=4.2)$ than nonabused women $(M=19.6, S=3.7), t(163)=1.73, p<.09$. (Note: Higher SES scores reflect lower socioeconomic status). Survivors were also more likely to be married at the time of the study (i.e., currently married or cohabiting; $24.5 \%$ ) as compared to nonabused women $(9.2 \%), \chi^{2}(1)=6.6, p<.01$. No differences between survivors and nonabused women were detected with regard to race.

Next, four $t$-tests were conducted to test the hypotheses that survivors would report poorer adjustment on the dependent measures of relationship satisfaction (QMI), the two trust scales (Reliableness and Emotional Trust), and communication (MCI). Results revealed significant effects for survivor status for the QMI, $t(162)=2.2, p<.03$, with survivors $(M=-1.4, S D=6.5)$ reporting lower relationship satisfaction than nonabused women $(M=0.6, S D=4.5)$. Differences were also found on the MCI, $t(164)=2.75, p<.007$, with survivors $(M=$ $101.3, S D=22.7)$ reporting poorer communication than nonabused women $(M=109.6, S D=15.5)$. At this stage of the analyses, no significant differences were found between groups on the Reliableness or Emotional Trust scales of the SITS. 
Given the previously noted differences between survivors and nonabused women on demographic characteristics, a series of analyses were conducted to determine if group differences would exist even after these variables were controlled. For this purpose four ANCOVAs were conducted with marital status, age, and SES serving as covariates. Overall, even with marital status, age, and SES controlled, group differences remained for the QMI, $F(1,144)=8.30, p<.005$, with survivors $(M=-1.8)$ reporting less relationship satisfaction than nonabused women $(M=0.8)$. A significant effect also remained on the $\mathrm{MCl}, F(1,146)=9.34, p<.003$, with survivors $(M=100.9)$ reporting poorer communication than nonabused women $(M=110.4)$. Thus, these results were similar to those obtained in the initial $t$-test analyses.

With regard to the trust measure, once marital status, age and SES were controlled, a previously obscured significant difference emerged on the Reliableness scale of the SITS, $F(1,145)=4.72, p<.03$, with survivors $(M=7.8)$ reporting less of the reliability component of trust in their partners than their nonabused counterparts $(M=8.2)$. Finally, these analyses also revealed a trend toward a difference on the Emotional trust scale of the SITS, $F(1,145)=2.98, p<.09$, again with survivors $(M=8.0)$ reporting less trust in their partners than nonabused women $(M=8.3)$.

\section{DISCUSSION}

Despite numerous anecdotal descriptions of the deleterious effects CSA may have upon adult couple functioning, very little empirical research has documented these outcomes. The present study employed standardized measures to investigate multiple aspects of couple relationships that may be impacted by a history of sexual abuse. Here, in a controlled study, results suggest that CSA negatively affects adult couple functioning, or at least survivors' perceptions of such functioning. More specifically, compared to nonabused participants, CSA survivors reported lower overall satisfaction, poorer communication, and less trust in their intimate relationships with partners. Various interpretations of these findings can be made, depending upon the specific theoretical position taken regarding the mechanisms by which the effects of child sexual abuse are manifested (e.g., cognitive-behavioral, systems, object relations). Several authors (e.g., Gelinas, 1988; Herman, 1981; Sgroi \& Bunk, 1988) have suggested that faulty learn- 
ing experiences during childhood are responsible for the interpersonal problems experienced by adult CSA survivors. Because the difficulties in couple relationships reported by these survivors are likely to have similar origins, explication of the present findings will be drawn largely from this general perspective. Also, because the vast majority $(96 \%)$ of survivors in the study were abused by male perpetrators, this discussion will be limited to female survivors abused by men.

In the first area of functioning examined, sexually victimized participants reported significantly less satisfaction than nonabused women in their relationships with their partners; these differences remained even when the demographic variables of marital status, age and SES were controlled. It may be that women abused as children by male perpetrators respond to their abuse by developing a set of negative beliefs and attitudes about males (e.g., all men have the potential to be hurtful and dangerous). As children, such beliefs likely serve a self-protective function. However, if generalized to their adult relationships with partners, such beliefs may lead to increased relationship conflict, and contribute to decreased overall relationship satisfaction. An alternative explanation for this finding is that the individual psychological and adjustment difficulties experienced by many survivors (e.g., depression, anxiety, poor self-esteem, substance abuse) may impact relational patterns with partners, resulting in lower overall satisfaction. This outcome would be consistent with other research (e.g., Jacobson, Waldron, \& Moore, 1989) showing that couples in which one member has been diagnosed with mental health problems are also at a higher risk for other difficulties, such as relationship distress.

Even accounting for group demographic differences, survivors also reported poorer communication than nonabused women in their couple relationships. Low scores on the MCI are suggestive of a variety of communication difficulties between partners, including low levels of self-disclosure, empathy, and general discourse, as well as greater frequency of aversive interactions, and poor conflict management skills (Schumm, Anderson, \& Griffin, 1983). Dysfunctional communication patterns among survivor couples could result from behaviors learned at the time of the abuse. Survivors' families of origin are often characterized by high levels of conflict and frequent negative interactions among members (Long \& Jackson, 1994). Such families, particularly those that are incestuous, may have valued secrecy and privacy, rather than open, direct communication between members. As chil- 
dren, maintaining secrecy about the abuse, as well as other significant areas of their lives, may have fostered a sense of control for survivors (Sgroi \& Bunk, 1988). However, such patterns having become ingrained during childhood could become a barrier to effective communication in adult couple relationships.

Survivors and nonabused women were also expected to differ regarding their ability to trust their partners. Although initial analyses revealed no differences on this measure, follow-up analyses accounting for demographic discrepancies revealed that survivors had significantly lower scores on the Reliableness component of the SITS, indicating a tendency to believe that others will break promises or fail to uphold commitments (Johnson-George \& Swap, 1982). Survivors were also somewhat different than nonabused women on the Emotional trust scale, which signifies problems confiding in others and believing that others are credible and honest (Johnson-George \& Swap, 1982).

Finkelhor and Browne's (1988) model may shed light upon the origins of the mistrust reported by the survivors in this study. Following abuse, child survivors often come to realize that someone they trusted has been dishonest and manipulative. They may feel betrayed not only by the perpetrator, but also by other family members who were perceived to be aware of the abuse but did nothing to intervene. This powerful experience of betrayal resulting from the abuse may impact survivors' interpersonal trust in varying ways. Having been victimized by people whom they formerly trusted, some incest survivors may feel particularly vulnerable and fearful of future abuse in their intimate relationships, and therefore perceive lower levels of trust in partners. Other survivors, in hopeful but hasty attempts to establish intimacy, may place trust in (sometimes undeserving) partners prematurely, rather than building it incrementally over time. Several clinicians (e.g., Courtois, 1979; Meiselman, 1990; Steele \& Alexander, 1981) have commented on survivors' tendencies toward dichotomous thinking (i.e., trusting no one or trusting inappropriately). This inclination may be revealed most clearly in the context of intimate relationships.

Results of this study provide additional support for a relationship between CSA and later relational difficulties. However, several limitations exist regarding the conclusions which can be drawn on the basis of these findings. First, this study relies upon participants' retrospec- 
tive reports of sexual experiences during childhood, which are subject to distortions due to intervening experiences. Second, because participants were female college students, these findings are not generalizable to male survivors, and may not apply to female survivors at later developmental stages, or to women involved in even longer-term, more established relationships. Third, this study was based only upon female survivors' perceptions of their intimate relationships. Because data from male partners or outside neutral observers was not obtained, reliable conclusions cannot be made about actual couple functioning. Finally, the abuse history of male partners was not assessed here, and thus the potential influences of their past victimization upon the dyad remains unknown.

These findings have important implications for work with survivors in clinical settings. Given the likelihood that survivors experience relationship difficulties, in addition to individual issues resulting from their abuse, it may be beneficial for clinicians to offer flexible treatment packages that include couples as well as individual therapy. In a thorough discussion of this issue, Kirschner, Kirschner, and Rappaport (1993) acknowledge that some partners may be reluctant to participate, but add that partner involvement is critical during the middle and latter stages of treatment. When effective and utilized appropriately, conjoint therapy can foster the development of both individuals within the relational context, and can dispel the myth that survivors are the only people with issues affecting the couple. Kirschner et al. (1993) further note that spouses have been successfully included in the treatment of individuals with anxiety and depressive disorders (Barlow, O'Brien, \& Last, 1984; Coyne, 1987), and since survivors often experience these same problems, it makes sense to include partners in their treatment as well. This approach contrasts with traditional treatments of CSA in which partners have been included in survivors' individual therapy in an ancillary role, primarily to support and facilitate the identified patient's (i.e., the survivor's) individual adjustment.

Therapists should be cognizant of the possibility that the interpersonal difficulties, such as those reported by these survivors, may generalize to the therapeutic relationship. Not only is therapeutic trust crucial when working individually with survivors, but it can become particularly salient during couples work, when for example, survivors may feel that the positive alliance they have already established with the therapist becomes jeopardized by the inclusion of partners in treat- 
ment. Meiselman (1990) offers several suggestions to help build and maintain trust in the therapeutic alliance, including the avoidance of dual relationships and breaches of confidentiality, keeping schedule changes to a minimum, and generally interacting in a consistent, reliable manner with survivors. Several authors (e.g., Kirschner et al., 1993; Meiselman, 1990) present excellent, detailed discussions of the role of trust issues in the treatment of sexual abuse survivors.

Additional research is needed to further delineate the relationship between childhood sexual abuse and later couple functioning. In light of the present findings that several important aspects of survivors' relationships can be negatively impacted by a history of sexual abuse, it would be useful to explore the potential effects of CSA upon other specific areas of couple functioning, such as intimacy, control, and decision making. In addition, this study examined couple functioning from the perspective of survivors only. However, it has been reported (e.g., Chauncey, 1994) that male partners of female sexual abuse survivors also experience relationship difficulties arising from the survivors' abuse history. Thus, additional studies should include both members of the dyad in order to obtain a more complete understanding of the effects of CSA upon couple functioning.

\section{REFERENCES}

Barlow, D. H., O'Brien, G. T., \& Last, C. (1984). Couples treatment of agoraphobia. Behavior Therapy, 15, 41-58.

Bienvenu, M. J. (1970). Measurement of marital communication. The Family Coordinator, 19, 26-31.

Briere, J., \& Runtz, M. (1988). Multivariate correlates of childhood psychological and physical maltreatment among university women. Child Abuse and Neglect, 12, 331-341.

Browne, A., \& Finkelhor, D. (1986). Impact of child sexual abuse: A review of the research. Psychological Bulletin, 99, 66-77.

Chauncey, S. (1994). Emotional concerns and treatment of male partners of female sexual abuse survivors. Social Work, 39, 669-676.

Cole, P. M. \& Putnam, F. W. (1992). Effect of incest on self and social functioning: A developmental psychopathological model. Journal of Consulting and Clinical Psychology, 60, 174-183.

Cole, P. M., Woolger, C., Power, T. G., \& Smith, K.D. (1992). Parenting difficulties among adult survivors of father-daughter incest. Child Abuse and Neglect, 16, 239-249.

Collins, J. D. (1977). Experimental evaluation of a six-month conjugal therapy and relationship enhancement program. In B.G. Guerney, Jr. (Ed.), Relationship Enhancement (pp. 226-231). San Francisco: Jossey-Bass. 
Conners, M. E. \& Morse, W. (1993). Childhood sexual abuse and eating disorders: A review. International Journal of Eating Disorders, 13, 1-11.

Courtois, C. A. (1979). The incest experience and its aftermath. Victimology: An International Journal, 4, 337-347.

Coyne, J. C. (1987). Depression, biology, marriage and marital therapy. Journal of Marital \& Family Therapy, 13, 393-407.

Davis, L. (1991). Allies in Healing. New York: Harper Collins.

Engle, B. (1991). Partners in recovery: How mates, lovers, and other prosurvivors can learn to support and cope with adult survivors of childhood sexual abuse. Los Angeles: Lowell House.

Finkelhor, D. \& Browne, A. (1985). The traumatic impact of child sexual abuse: A conceptualization. American Journal of Orthopsychiatry, 55, 530-541.

Finkelhor, D. \& Browne, A. (1988). Assessing the long-term impact of child sexual abuse: A review and conceptualization. In G.T. Hotaling, D. Finkelhor, J.T. Kirkpatrick, \& M. A. Straus (Eds.), Family Abuse and Its Consequences: New Direction in Research (pp. 270-284). Newbury Park, CA: Sage Publications.

Finkelhor, D., Hotaling, G. T., Lewis, I. A., \& Smith, C. (1990). Sexual abuse in a national survey of adult men and women: Prevalence, characteristics and risk factors. Child Abuse and Neglect, 14, 19-28.

Finkelhor, D., Hotaling, G. T., Lewis, I. A., \& Smith, C. (1989). Sexual abuse and its relationship to later sexual satisfaction, marital status, religion, and attitudes. Journal of Interpersonal Violence, 4, 379-399.

Gelinas, D. J. (1988). Family therapy: Characteristic family constellations and basic therapeutic stance. In S. M. Sgroi (Ed.), Vulnerable populations: Evaluation and treatment of sexually abused children and adult survivors (Vol. 1, pp. 25-49). Lexington, MA: Lexington Books.

Gil, E. (1992). Outgrowing the pain together: A book for spouses and partners of adults abused as children. New York: Bantam Books.

Graber, K. (1991). Ghosts in the bedroom: A guide for incest survivors. Deerfield Beach, FL: Health Communications.

Guerney, B. G., Jr. (1977). Relationship enhancement. San Francisco: Jossey-Bass.

Hansen, P. A. (1991). Survivors and partners: Healing the relationships of sexual abuse survivors. Longmont, CO: Herrn Hill Publishing Co.

Harter, S., Alexander, P. C., \& Neimeyer, R. A. (1988). Long-term effects of incestuous child abuse in college women: Social adjustment, social cognition, and family characteristics. Journal of Consulting and Clinical Psychology, 56, 5-8.

Herman, J. L. (1981). Father-daughter incest. Cambridge, MA: Harvard University Press.

Herman, J. L., Perry, J. C., \& van der Kolk, B. A. (1989). Childhood trauma in borderline personality disorder. American Journal of Psychiatry, 146, 490-495.

Hunter, J. A. (1991). A comparison of the psychosocial maladjustment of adult males and females sexually abused as children. Journal of Interpersonal Violence, $6(2)$, 205-217.

Jackson, J. L., Calhoun, K. S., Amick, A. A., Maddever, H. M., \& Habif, V. L. (1990). Young adult women who report childhood intrafamilial sexual abuse: Subsequent adjustment. Archives of Sexual Behavior, 19, 211-221. 
Jacobson, N. S., Waldron, H., \& Moore, D. (1989). Toward a behavioral profile of marital distress. Journal of Consulting and Clinical Psychology, 48, 696-703.

Johnson-George, C., \& Swap, W. C. (1982). Measurement of specific interpersonal trust: Construction and validation of a scale to assess trust in a specific other. Journal of Personality and Social Psychology, 43, 1306-1317.

Kirschner, S., Kirschner, D. A., \& Rappaport, R. L. (1993). Working with adult incest survivors/The healing journey. New York: Brunner/Mazel.

Kritsberg, W. (1990). Healing together. Deerfield Beach, FL: Health Communications.

Linehan, M. M. (1993). Cognitive-behavioral treatment of borderline personality disorder. New York: Guilford Press.

Long, P. J. (1998). Assessing a history of childhood sexual abuse in adults: The Life Experiences Questionnaire. Manuscript in preparation. Oklahoma State University, Stillwater.

Long, P. J. \& Jackson, J. L. (1994). Childhood sexual abuse: An examination of family functioning. Journal of Interpersonal Violence, 9, 270-277.

Maltz, W. (1988). Identifying and treating the sexual repercussions of incest: A couples therapy approach. Journal of Sex and Marital Therapy, 14, 142-170.

Meiselman, K. C. (1990). Resolving the trauma of incest. San Francisco: JosseyBass.

Messner, S., Shipp, D., Jackson, J. L., Edison, J., Townsley, R., Burke, M., Chandler, K., \& Long, P. J. (1988, March). Reliability of adults' reports of childhood sexual abuse. Paper presented at the annual meeting of the Southeastern Psychological Association. New Orleans, LA.

Mullen, P. E., Martin, J. L., Anderson, J. C., Romans, S. E., \& Herbison, G. P. (1994). The effect of child sexual abuse on social, interpersonal, and sexual function in adult life. British Journal of Psychiatry, 165, 35-47.

Myers, J. K., \& Bean, L. L. (1968). A decade later: A follow up of social class and mental illness. New York: Wiley.

Norton, R. (1983). Measuring marital quality: A critical look at the dependent variable. Journal of Marriage and the Family, 15, 141-151.

Peters, S. D. (1988). Child sexual abuse and later psychological problems. In G. E. Wyatt \& G. F. Powell (Eds.), Lasting effects of child sexual abuse (pp. 101-117). Newbury Park, CA: Sage.

Peters, S. D., Wyatt, G. E., \& Finkelhor, D. (1986). Prevalence. In D. Finkelhor \& Associates, A sourcebook on child sexual abuse (pp. 15-59). Beverly Hills, CA: Sage Publications.

Polusny, M. A., \& Follette, V. M. (1995). Long-term correlates of child sexual abuse: Theory and review of the empirical literature. Applied and Preventive Psychology, 4, 143-166.

Rubin, Z. (1970). The measurement of romantic love. Journal of Personality and Social Psychology, 16, 265-273.

Salter, A. C. (1992). The epidemiology of child sexual abuse. In W. O'Donahue \& J. $\mathrm{H}$. Geer (Eds.), The sexual abuse of children: Vol. 1. Theory and research. Hillsdale, NJ: Erlbaum \& Associates. 
Schumm, W. R., Anderson, S. A., \& Griffin, C. L. (1983). The Marital Communication Inventory. In E. E. Filsinger (Ed.), Marriage and family assessment: A sourcebook for family therapists (pp. 191-208). Beverly Hills: Sage.

Schumm, W. R., \& Jackson, R. W. (1980). Marital communication or marital adjustment? A brief report on the Marital Communication Inventory. Psychological Reports, 46, 441-442.

Serafin, J. M. \& Follette V. M. (1996, November). The impact of sexual trauma on survivor couple relationships. Paper presented at the annual meeting of the Association for the Advancement of Behavior Therapy.

Sgroi, S. M., \& Bunk, B. S. (1988). Family therapy: Characteristic family constellations and basic therapeutic stance. In S. M. Sgroi (Ed.), Vulnerable populations: Evaluation and treatment of sexually abused children and adult survivors (Vol. 1, pp. 137-186). Lexington, MA: Lexington Books.

Stark, K. (1993). Helping the adult survivor of child sexual abuse: For friends, family, and lovers. Racine, WI: Mother Courage Press.

Steele, B. F., \& Alexander, H. (1981). Long-term effects of sexual abuse in children. In P. B. Mrazek \& C. H. Kempe (Eds.), Sexually abused children and their families. (pp. 223-234). Elmsford, NY: Pergamon Press.

Waltz, J. (1996, November). The impact of trauma on functioning in couple relationships. In J. Waltz (Chair), Couples relationship functioning in female child sexual abuse survivors and their partners. Symposium conducted at the annual meeting of the International Society for Traumatic Stress Studies. San Francisco, CA.

Wind, T. W. \& Silvern, L. (1992). Type and extent of child abuse as predictors of adult functioning. Journal of Family Violence, 7, 261-281.

Wyatt, G. E. (1988). The relationship between childhood sexual abuse and adolescent sexual functioning in Afro-American and White American women. Annals of the New York Academy of Sciences, 528, 111-122.

Wyatt, G. E., Guthrie, D., \& Notgrass, C. M. (1992). Differential effects of women's childhood sexual abuse and subsequent sexual revictimization. Journal of Consulting and Clinical Psychology, 60, 167-173.

Yama, M. F., Tovey, S. L., \& Fogas, B. S. (1993). Childhood family environment and sexual abuse as predictors of anxiety and depression in adult women. American Journal of Orthopsychiatry, 63, 136-141. 